\title{
IN-SITU AGING OF ROOF SYSTEMS CONTAINING POLYISOCYANURATE ROOF INSULATION FOAMED WITH ALTERNATIVE BLOWING AGENTS
}

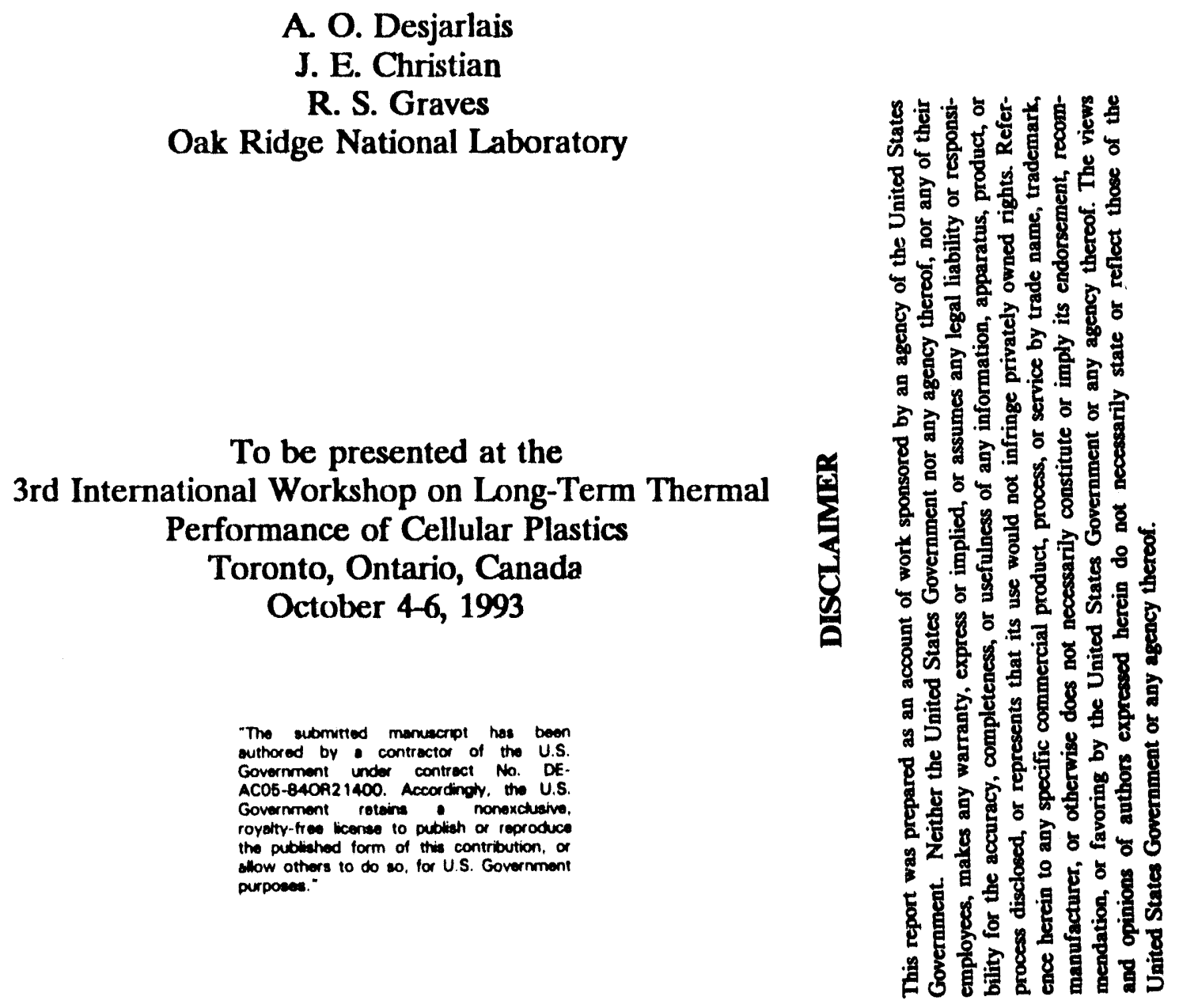

Research sponsored by the Office of Building Technologies, U.S. Department of Energy, under Contract No. DE-AC05-84OR21400 with Martin Marietta Energy Systems, Inc.

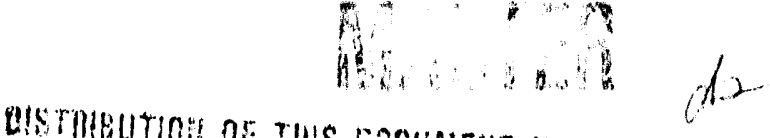

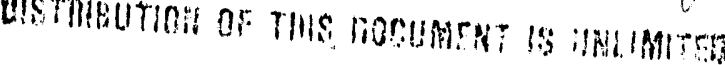

SEP $29\{93$

OSt 


\title{
IN-SITU AGING OF ROOF SYSTEMS CONTAINING POLYISOCYANURATE ROOF INSULATION FOAMED WTTH ALTERNATTVE BLOWING AGENTS
}

\author{
by \\ A.O. Desjarlais, J.E. Christian, and R.S. Graves \\ Oak Ridge National Laboratory \\ Building Thermal Envelope Systems and Materials Program
}

\section{ABSTRACT}

Experimental polyisocyanurate (PIR) foam roof insulations with permeable facers were installed in roofing systems and continuously monitored for thermal performance for four years. The foams were produced using a specific formulation that represented current technology in 1989 and were blown with $\mathrm{CFC}-11, \mathrm{HCFC}-123$, and HCFC-141b. These foams were installed in roof systems comprised of loose-laid insulation boards covered by either a loosely-laid single ply white or black membrane.

The in-situ testing was carried out on an outdoor test facility, the Roof Thermal Research Apparatus (RTRA). Additional specimens of these foams were aged in the laboratory and periodically evaluated using laboratory measurement equipment. This paper will summarize the insitu data compiled to date, compare these data with the laboratory results, and examine whether the proposed laboratory procedure for accelerating the aging of foams by the slicing and scaling method accurately predicts the aging characteristics of these materials installed in roof systems.

These experiments are part of a joint industry/government project established to cvaluate the technical viability of alternative HCFC blowing agents for rigid closed-cell polyisocyanurate foam roof insulations. Members of the project are the U.S. Department of Energy (DOE)/Oak Ridge National Laboratory (ORNL), the U.S. Environmental Protection Agency (EPA), the Society of the Plastics Industry-Polyurethane Division (SPI), the Polyisocyanurate Insulation Manufacturers Association (PIMA), and the National Roofing Contractors Association (NRCA). 


\section{INTRODUCTION}

A joint industry/government project was initiated in 1989 to assess the technical viability of alternative blowing agents in polyisocyanurate (PIR) foam roof insulation. Some of the project objectives were to determine the thermal performance of polyisocyanurate foam roof insulation blown with alternative blowing agents, to compare their performance with boards produced with CFC-11, and to devise and validate a laboratory procedure for accelerating the thermal aging process. Elements of this project have been previously reported by Baumann [1], Blanpied and Knis [2], McElroy, et al. [3], Christian, et al. [4], Graves, et al., [5], Courville, et al. [6], Smith, et al. [7], Christian, et al. [8], and Desjarlais, et al. [9]. Baumann reported the history leading up to the establishment of the cooperative effort, Blandpied described the processing parameters to produce the experimental foam products and their physical characteristics, McElroy reported the on the laboratory experiments that were performed, and Christian (Ref 4) related the details of the in-situ experiments. Graves presented some early comparisons between the slicing and in-situ data, Courville discussed alternative means of analyzing the in-situ data, and Smith reviewed the physical performance of the various in-situ roofing applications. Christian (Ref 8) extended his comparisons of Reference 4 to include the impact of a variety of roofing systems and Desjarlais discussed whether the various in-situ roofing applications impacted the aging characteristics of the foam.

Aging has been defined as the change in thermophysical properties of a rigid closed cell foam with time primarily due to changes in the composition of the gas contained within the closed cells. The need for a laboratory test method for accelerating the thermal aging of closed cell plastic foams has been well documented. Standards organizations such as the American Society for Testing and Materials (ASTM), International Standards Organization (ISO), the Community of European Nations (CEN), and Nordtest have in place or are in the process of developing standard test protocols. Data that validates the accelerated test methods, especially results that represent actual installed thermal performance, are sparse. This paper reports results compiled on specimens of polyisocyanurate foam with alternative blowing agents that have been gathered using an accelerated laboratory procedure and compares these data with in-situ data on specimens from the same lots of materials. 


\section{LABORATORY TEST FACILITIES}

Laboratory measurements reported in this paper were performed using the ORNL heat flow meter apparatus (HFMA) or the ORNL unguarded thin heater apparatus (UTHA) [10]. Specimens of polyisocyanurate foam blown with CFC-11, HCFC-123, and HCFC-141b were prepared from permeably faced $1.2 \times 2.4 \mathrm{~m}$ boards that were manufactured by a PIMA member in June 1989. The formulation was not optimized for thermal performance or any specific blowing agent.

Two series of measurements were performed. The first group of experiments was performed to ascertain whether geometric scaling is applicable to permeably faced polyisocyanurate foam. For each of the three foam types, $600 \mathrm{~mm}$-square specimens were prepared in three nominal thicknesses, namely 10,19 , and $33 \mathrm{~mm}$. Test samples were fabricated from these specimens by stacking four layers of $10 \mathrm{~mm}$ specimens, two layers of $19 \mathrm{~mm}$ specimens, or a single layer of the $33 \mathrm{~mm}$ specimen. These specimens were conditioned in a laboratory environment maintained at $24^{\circ} \mathrm{C}$ and periodically measured for apparent thermal conductivity over a period of approximately 900 days after manufacture. All of these experiments were undertaken on the HFMA apparatus.

The second group of experiments was performed to investigate the effect of mean temperature on apparent thermal conductivity. These experiments were also used to support the insitu measurements in that the tests were performed on the central $600 \mathrm{~mm}$ square section of each insitu test panel. A complete description of these specimens is given in the following section. Prior to the initiation of the in-situ testing, these specimens were evaluated at up to six mean temperatures ranging from 0 to $50^{\circ} \mathrm{C}$. Once the in-situ aging experiments had started, they were periodically interrupted for a short period of time so that the central section could be removed and returned to the laboratory for retesting. Both the HFMA and the UTHA apparatus were used for these tests.

\section{OUTDOOR TEST FACILITIES AND ROOFING SYSTEMS}

The in-situ experiments reported in this paper were undertaken on the Roof Thermal Research Apparatus (RTRA) which is shown in Figure 1. The RTRA is a 3 by $8.5 \mathrm{~m}$ conditioned 
building that can accommodate four 1.2 by $2.4 \mathrm{~m}$ roof test panels exposed to environmental conditions at its location in East Te'nnessee. Data from two of these panels are reported in this paper. A schematic diagram of a typical panel is depicted in Figure 2. Each test panel was divided into two $1.2 \mathrm{~m}$ square specimens. Two $38 \mathrm{~mm}$ layers of foam were stacked and laid over a continuous metal deck. Loose-laid EPIMM membranes were placed over each specimen and attached along the perimeter to seck a weather-tight seal. The central $600 \mathrm{~mm}$ square section of each foam test specimen was physically scparated from the remaining foam so that it could be periodically removed to measure its thermal performance and calibrate the installed instrumentation. Computer simulation was performed to guarantee that the central sections were free of thermal anomalies due to the edges.

The test panel on the far left in Figure 1 contained HCFC-141b blown foam in both specimens. One of these specimens was covered with a white EPDM membrane; the second specimen was covered with a black EPDM membrane. The test panel shown on the far right of Figure 1 contained specimens of CFC-11 and HCFC-123 blown foam. Bott of these specimens were covered with a black EPDM membrane. A comparison of the data from the roofing systems covered with membranes of different reflectance is given in Reference 11; all in-situ data presented in this paper were acquired on roofing systems under a black EPDM membrane.

Each specimen was instrumented with a $50 \mathrm{~mm}$ square heat flux transducer (HFT), which was mounted between the insulation layers and Type $\mathrm{T}$ copper-constantan thermocouples, which were installed at each internal interface (between the EPDIM and the top foam layer, between the foam layers, and between the bottom foam layer and the metal deck). The instrumented boards were installed in the RTRA in October 1989 and data collection began at that time.

\section{DATA COLLECTION AND ANALYSES}

\section{Laboratory Testing}

Acceleration of foam aging through thin slicing has been demonstrated to producc reliable results. The evidence is the use of laboratory instrumentation to compare aging rate data from scveral thicknesses of the same material [12]. A scaling factor has been defined by ASTM as the 
acceleration rate which is being applied to the aging process due to the difference in thickness between the specimen undergoing test $\left(\Delta X_{2}, \mathrm{~mm}\right)$ and the thickness of the material for which aging data is desired $\left(\Delta X_{1}, \mathrm{~mm}\right)[13]$. The scaling factor, $t^{0.5} / \Delta X$ (days $0.5 / \mathrm{mm}$ ), is proposed as a means of translating aging data of thin slices over short test times to production thicknesses over the service life of the materials.

A summary of the laboratory measurements on three thicknesses of HCFC-141b blown polyisocyanurate foam is depicted in Figure 3. By plotting $\ln \lambda$ vs. $t^{0.5} / \Delta X$, two linear regions describing the primary and secondary stages of aging are defined [10]. Least squares curve fits were performed on each region; the standard error is less than 2 percent for the HCFC-141b data presented in Figure 3. Similar data were compiled on CFC-11 and HCFC-123 blown polyisocyanurate foam; comparable agreement was found between the various thick hesses when geometric scaling was applied to the test data.

\section{In-Situ Testing}

Temperature and heat flux data from the sensors installed in the test panels were automatically recorded in one-minute intervals and averaged into hourly values. A computer program PROPOR (Properties - Oak Ridge) was used to compute the thermal performance of the insulation. PROPOR is an application of one-dimensional inverse heat transfer analysis and has been reported by Beck et al [14] and Beck and Arnold [15]. Using a time series of boundary conditions and initial estimates of thermal properties, PROPOR predicts the temperatures and heat fluxes at sensor locations utilizing the conduction heat transfer equation for a homogeneous medium. The program then recomputes the measured parameters to predict a better set of thermal properties and continues this process until a predetermined error limit is reached. As configured for this project, the final output of PROPOR is a linear ( 2 point) estimate of thermal conductivity vs. temperature for a fixed heat capacity (product of density and specific heat). PROPOR was applied to weekly (168 hour) sets of data and was used to estimate the combined thermal properties of the two insulation boards.

An example of these results, data compiled on HCFC-141b blown polyisocyanurate foam, is presented in Figure 4. Since each data point was computed from a different week's data, the meteorological conditions for that week dictate the mean tenipcrature for the insulation material. 
These mean temperatures vary significantly over the course of the year, ranging from 5 to $35^{\circ} \mathrm{C}$. To adjust the in-situ data to a common mean temperature, the laboratory test data on the central sections of the in-situ test panels was measured as a function of mean temperature and time. Data on the HCFC-141b blown polyisocyanurate foam in-situ test panel compiled during this project are shown in Figure 5. Similar relationships were developed for the other blowing agents.

Utilizing the relationship between apparent thermal conductivity and temperature that was measured at a time that most closely approximates the in-situ test data, the in-situ data was normalized to a mean temperature of $24^{\circ} \mathrm{C}$. The impact of this adjustment on the HCFC-141b data is depicted in Figure 4. Normalized apparent thermal conductivities for data gathered during the winter periods (around days 180,550,900, and 1300) are larger than the measured values because the mean temperatures for these periods of time are lower than $24^{\circ} \mathrm{C}$. The normalization of the apparent thermal conductivity test data to a constant mean temperature has the opposite effect on data compiled during the summer.

Figure 6 presents just the normalized data for the CFC-11, HCFC-123, and HCFC-141b blown polyisocyanurate foams. For the first four ycars (1455 days), the HCFC-123 and HCFC-141b blown foams were approximately 4 and 10 percent higher in normalized apparent thermal conductivity than the foam produced with CFC-11, respectively.

\section{EXPERIMENTAL RESULTS AND DISCUSSION}

To measure the predictive capability of the slicing technique, the $10 \mathrm{~mm}$ apparent thermal conductivity data for each type of blowing agent as a function of relative time were curve-fitted in a piece-wise linear manner and compared to the in-situ apparent thermal conductivity data for the period of time that the in-situ experiment was performed. These results for the HCFC-141b blown PIR foam are presented in Figure 7. The in-situ and laboratory data were integrated over five time intervals: $0-180$ days, $0-365$ days, $0-730$ days, $0-1095$ days, and $0-1455$ days. These intervals were sclected to represent the present recommendation for aging prior to determining the thermal performance of PIR foam (0-180 days), as well as yearly intervals (0-365 days, 0-730 days, and 0-1095 days), and the entire data set that was analyzed to date (0-1455 days). 
A summary for all three blowing agents of the differences between the lab slicing prediction and the in-situ data for the various integration periods are presented in Figure 8. The agreement between the individual predictions from the lab slicing procedure and the in-situ data is excellent, ranging from 0.2 to 5.9 percent. In all cases, the laboratory prediction slightly underestimates the insitu apparent thermal conductivity data. The best agreement for all three blowing agents occurs with the earliest data; the 0-180 day integration period apparent thermal conductivity data predicted by the laboratory procedure averages 1.2 percent lower than the in-situ results. However, a time dependent relationship does not appear in the remaining data. The apparent thermal conductivity data computed from the laboratory procecure for the integration periods of 0-365 days, 0-730 days, 0-1095 days, and 0-1455 days are 2.7, 2.5, 3.4, and 2.8 percent, respectively, below the in-situ data. For the four-year time period that the in-situ experiment was monitored, the $10 \mathrm{~mm}$ slice data measured over a period of approximately 110 days accurately predict the in-situ thermal performance of the PIR foam. In this project, the impact of the damaged layer of cells created when the thin slic: specimens were produced was entirely ignored. Thinner slices will yield greater acceleration rates; however, the damaged cells will begin to have a greater impact on the test results of thinner sections. The minimum thickness that can be used to accelerate aging while ignoring the impact of the damaged surface cells needs to be determined. For $10 \mathrm{~mm}$ slices, it is apparent that the surface cell damage can be ignored.

The agreement in the thermal performance predictions of the thin slice specimens and the in-situ experiments is outstanding given the differences in the conditioning of the specimens. The average temperature that the in-situ specimens were exposed to was $21.0^{\circ} \mathrm{C}$, but varied from -19 to $89^{\circ} \mathrm{C}$ over the four-year exposure. These specimens were exposed to severe temperature ramps and the potential for moisture pickup through the metal deck. Meanwhile, the thin slice specimens were held in a laboratory environment of $24^{\circ} \mathrm{C}$ for the duration of the project. Additionally, different analyses are applied to compute the thermal performance. But after four years, the apparent thermal conductivity of HCFC-141b blown PIR foam, the new generation of PIR, was predicted to within 3 percent by the laboratory thin slice method. 
Figure 9 displays a plot of the natural logarithm of the apparent thermal conductivity versus the scaling factor (the square root of the age divided by the thickness) for HCFC-141b blown PIR foam. The "In-Situ Data" are the normalized data measured in the roof system containing the appropriate blowing agent. The curve referred to as the "Slicing Curve Fit" was described earlier when Figure 3 was discussed and represents the least squares fit for all of the laboratory testing. The data set identific $\mathrm{J}$ as "In-Situ Curve Fit" represents the least squares fit of the in-situ data.

Reference 10 suggests that this manner of data presentation highlights two distinct linear regions of behavior with an intermediate transition zone and further proposes that the first linear r gion is associated with the increase in apparent thermal conductivity due to the influx of air components while the second linear region should be associated with the increase in apparent thermal conductivity associated with the loss of blowing agent. The slopes of these regions would therefore be proportional to the effective diffusion coefficients of air components and blowing agents, respectively.

Figure 10 summarizes the slopes of the two linear regions (primary and secondary stages) for the laboratory and in-situ experiments for all three blowing agents. For the primary stage, the slopes for the three PIR foams range from 0.29 to 0.33 for the laboratory experiments and 0.23 to 0.29 for the in-situ experiments. The average difference in the laboratory and in-situ slopes was approximately 18 percent. Given the difficulties in making precise diffusion coefficient measurements, the agreement between the laboratory and in-situ testing slopes is sufficient to consider this form of analysis for measuring effective diffusion coefficients. For the secondary stage, the average difference in the laboratory and in-situ slopes increased to over 100 percent. This variation is due to a combination of factors. First, the slopes of the secondary stage of aging are small, sensitizing the comparisons to the uncertainties of the test methods. In addition, since there presently is very little data from the in-situ experiment that is in the secondary stage of aging, the transition zone data have a considerable impact on the slope. Finally, the selection of the transition point from primary to secondary aging is imprecise. It is expected, however, that as more data become available, the difference in slope in the secondary stage will decrease appreciably since the influences of the selection of the transition point and the data in the transition zone will be diminished. 


\section{CONCLUSIONS}

Polyisocyanurate roof insulation blown with CFC-11, HCFC-123, and HCFC-141b, installed in roofing systems, has been exposed in an outdoor test facility at ORNL for almost four years. Temperature sensors and heat flux transducers installed in these systems have been employed to monitor the insulation's in-situ thermal response to natural weather conditions. A model of the systems has been used in conjunction with PROPOR to compute an estimate of the thermal properties of each type of PIR foam. Laboratory testing has been performed concurrent to the insitu investigations. Three thicknesses of foam specimens produced from the same batches as the insitu specimens have been periodically analyzed. The following conclusions can be drawn from this project.

1. For PIR roof insulation with permeable facers, the slicing and scaling laboratory procedure yields consistent results. Test results from three different thicknesses of PIR foam agree to within a standard error of less than two percent when geometrically scaled.

2. The accelerated laboratory procedure underestimates the apparent thermal conductivity of CFC-11, HCFC-123, and HCFC-141b blown PIR foams that have been aged in a low-slope roof system in the southern continental climate of Knoxville, TN by approximately 1 to 6 percent.

3. When inte ;rating the apparent thermal conductivity of the three types of PIR foam for various service lives rangin from 180 days to approximately four years, the accelerated laboratory procedure predicts the thermal performance of the in-situ experiments to within 6 percent or less. For the HCFC-141b blown PIR foam the agreement ranged from 0.2 to 2.8 percent.

4. The slopes of the plot of the natural logarithm of the apparent thermal conductivity versus the scaling factor, which are proportional to the effective diffusion coefficients, agree within 18 percent for the primary stage of aging. Insufficient data are presently available to compare the slopes for the secondary aging stage. 
5. A slice thickness of $10 \mathrm{~mm}$ for PIR foam is of sufficient thickness that the effects of the broken surface layer eclls can be ignored. Higher acceleration rates could be obtained using thinner slices, but the impact of broken surface cells would need to be reassessed.

\section{ACKNOWLEDGEMENTS}

The authors would like to thank the members of the stecring committee for their guidance and support, D.W. Yarbrough for his helpful conversations and input, and T.W. Petrie and _...R. Byerley for their careful reviews. This project was supported by the Office of Buildings Energy Research, U.S. Department, as part of the National Program Plan for Building Thermal Envelope Systems and Materials, managed by Martin Marietta Energy Systems, Inc. under Contract No. DEAC05-84-OR21400. 


\section{REFERENCES}

1. Baumann, G.F., "Are Alternative Blowing Agents Technically Viable for Polyisocyanurate Roof Insulation?," Polyurethanes 90, pp. 232-233, 1990.

2. Blanpied, R.H., and Knis, S.A., "The Technical Viability of Alternative Blowing Agents in Polyisocyanurate Roof Insulation. Part I: Processing and Physical Propertics," Polyurethanes 90, pp. 234-238, 1990.

3. McElroy, D.L., Graves, R.S., Weaver, F.J., and Yarbrough, D.W., "The Technical Viability of Alternative Blowing Agents in Polyisocyanurate Roof Insulation. Part II: Acceleration of Thermal Resistance Aging Using Thin Boards," Polyurethanes 90, pp. 239-246, 1990.

4. Christian, J.E., Courville, G.E., Linkous, R.L., Wendt, R.L., Graves, R.S., and Smith, T., "The Technical Viability of Alternative Blowing Agents in Polyisocyanurate Roof Insulation. Part 1II: In-Situ Thermal Aging and Performance in Different Roof Systems," Polyurethanes 90, pp. 247-259, 1990.

5. Graves, R.S., Christian, J.E., and McElroy, D.L., "Joint Industry/Government Research Project - Comparison of Thermal Aging for Roof Exposures and Thin Specimens of Experimental Polyisocyanurate Insulation Foamed with Alternative Blowing Agents," Proceedings of the Polyurethanes World Congress, pp. 385-398, 1991.

6. Courville, G.E., Christian, J.E., and Graves, R.S., "Thermal Conductivity of Polyisocyanurate Foam Board Insulation Blown with CFC-11 Substitutes; Laboratory and Long Term Ficld Measurements, "VIII Congreso Internacional da la Impermeabilzacion, Madrid, Spain, pp. 57. 68, 1992.

7. Smith, T.L., Childs, P.W., Christian, J.E., and Wendt, R.L., "Mechanical Properties Evaluation of Polyisocyanurate Roof Insulation with CFC-11 Substitutes," Proceedings of the Third International Symposium on Roofing Technology, pp. 143-150, NRCA, 1991.

8. Christian, J.E., Desjarlais, A.O., Courville, G.E., and Graves, R.S., "Roof System Effects on In-Situ Thermal Performance of HCFC Polyisocyanurate Foam," Polyurethanes 92, pp. 400. 409, 1992.

9. Desjarlais, A.O., Christian, J.E., and Linkous, R.L., "System Effects on the Thermal Aging of Experimental Polyisocyanurate Roof Insulation Foamed with an Alternative Blowing Agent," Thermal Performance of the Exterior Envelopes of Buildings V, pp. 391-398, ASHRAE/DOE/BTECC, 1992.

10. McElroy, D.L., Graves, R.S., Yarbrough, D.W., and Weaver, F.J., "Laboratory Test Results on the Thermal Resistance of Polyisocyanurate Foamboard Blown with CFC-11 Substitutes A Cooperative Industry/Government Project," Oak Ridge National Laboratory Report ORNL/TM-11645, 1991. 
11. Christian, J.E., Courville, G.E., Desjarlais, A.O., Graves, R.S., Linkous, R.L., McElroy, D.L., Weaver, F.J., Wendt, R.L., and Yarbrough, D.W., "The Technical Viability of Alternative Blowing Agents in Polyisocyanurate Roof Insulation: A Cooperative Industry/Government Project," Oak Ridge National Laboratory Report ORNL/CON-367, 1993.

12. Isberg, J., "Thermal Insulation - Conditioning of Rigid Cellular Plastics Containing a Gas with Lower Thermal Conductivity than Air Prior to Determination of Thermal Resistance and Related Properties," Chalmers University of Technology, No. 698, Goteberg, Sweden, 1988.

13. Proposed ASTM Standard Test Method for "Estimating the Long-Term Change in the Thermial Resistance of Unfaced Rigid Closed Cell Plastic Foams by Slicing and Scaling Under Controlled Laboratory Conditions," under development by ASTM Committee C16 on Thermal Insulations.

14. Beck, J.V., Petrie, T.W., and Courville, G.E., "Using Parameter Estimations to Analyze Building Envelope Thermal Performance," ASTM C-16 Workshop on In-Situ Heat Flux Measurements in Buildings, U.S. Army Corps of Engineers Cold Regions Research Engineering Laboratory Report, May, 1990.

15. Beck, J.V., and Arnold, K.J., "Parametric Estimations in Engineering and Science," John Wiley and Sons, New York, NY, 1978. 


\section{FIGURE CAPTIONS}

Figure 1: $\quad$ Photograph of the Roof Thermal Research Apparatus (RTRA) at Oak Ridge National Laboratory. The test panels discussed in this paper are on the far left and right of the roof.

Figure 2: $\quad$ Schematic top view of a RTRA test panel detailing the construction of the insulation layers.

Figure 3: Scaling three thicknesses of PIR foam blown with HCFC-141b demonstrates the effectiveness of the laboratory accelerated procedure in producing consistent results.

Figure 4: The apparent thermal conductivity of HCFC-141b blown PIR foam as measured in the in-situ test apparatus and after adjustment to a constant mean temperature of $24^{\circ} \mathrm{C}$.

Figure 5: The apparent thermal conductivity versus temperature relationships are used to normalize the in-situ test data to a constant mean temperature of $24^{\circ} \mathrm{C}$. Data shown in this figure were measured on a HCFC-141b blown PIR foam.

Figure 6: The normalized apparent thermal conductivity of PIR foam blown with CFC-11 and alternative blowing agents. These data are measured in-situ in a low-slope roof system.

Figure 7: $\quad$ The laboratory accelerated test procedure of slicing and scaling slightly underestimates the in-situ apparent thermal conductivity data. Data presented in this figure are for HCFC-141b blown PIR foam.

Figure 8: $\quad$ The integrated thermal performance of all three types of PIR foam measured in-situ agrees exceptionally well with the predictions of the accelerated laboratory aging procedure.

Figure 9: The slopes of the scaled and in-situ apparent thermal conductivity of the HCFC-141b blown PIR foam agree well in the primary stage of aging. Additional test data over a longer period of time are required for comparisons in the secondary stage.

Figure 10: The slopes of the primary stage aging curves measured in-situ and in the laboratory are in reasonable agreement. Data from the in-situ secondary stage are still sparse, and comparisons are difficult to make at this time. 


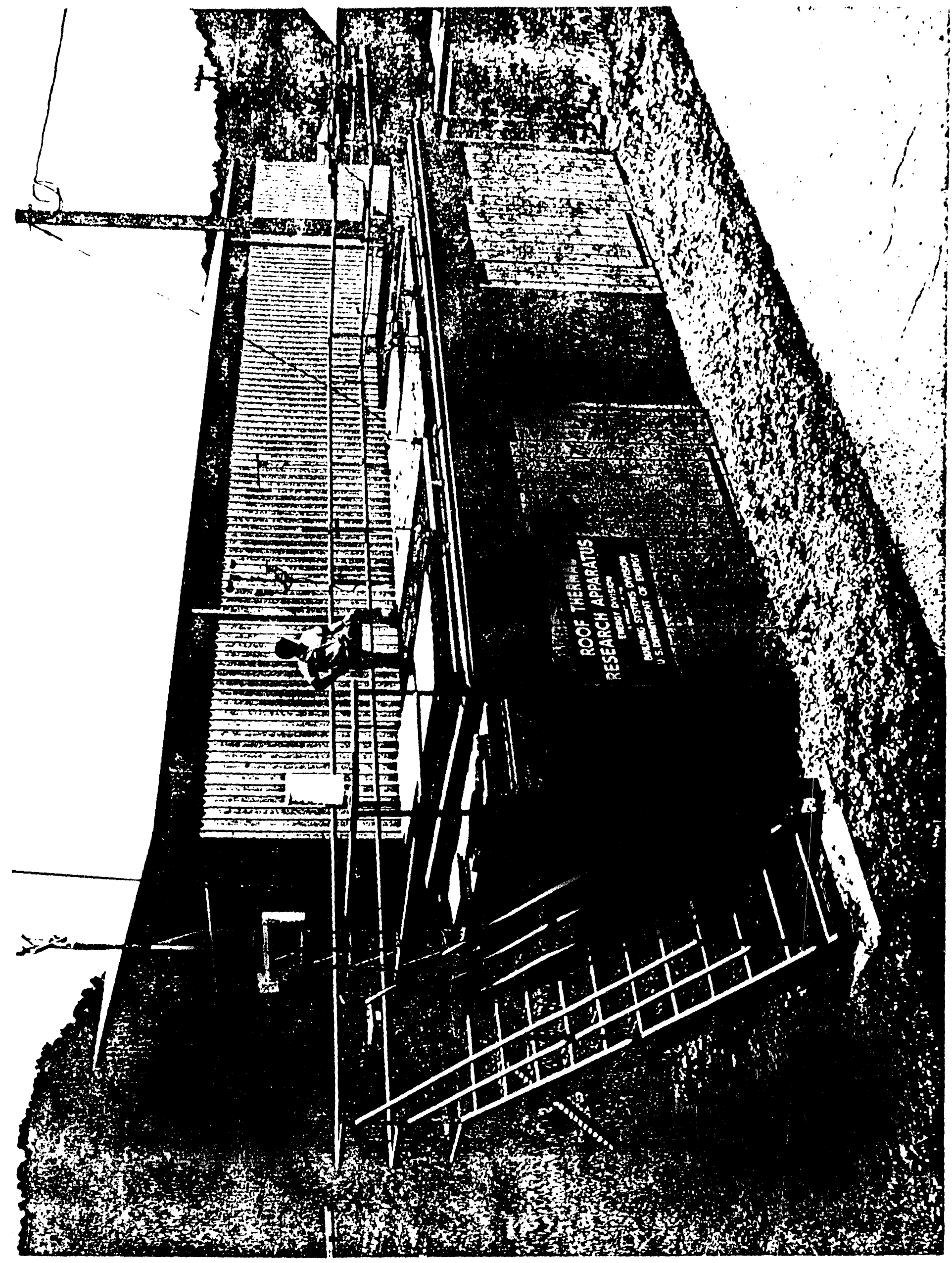




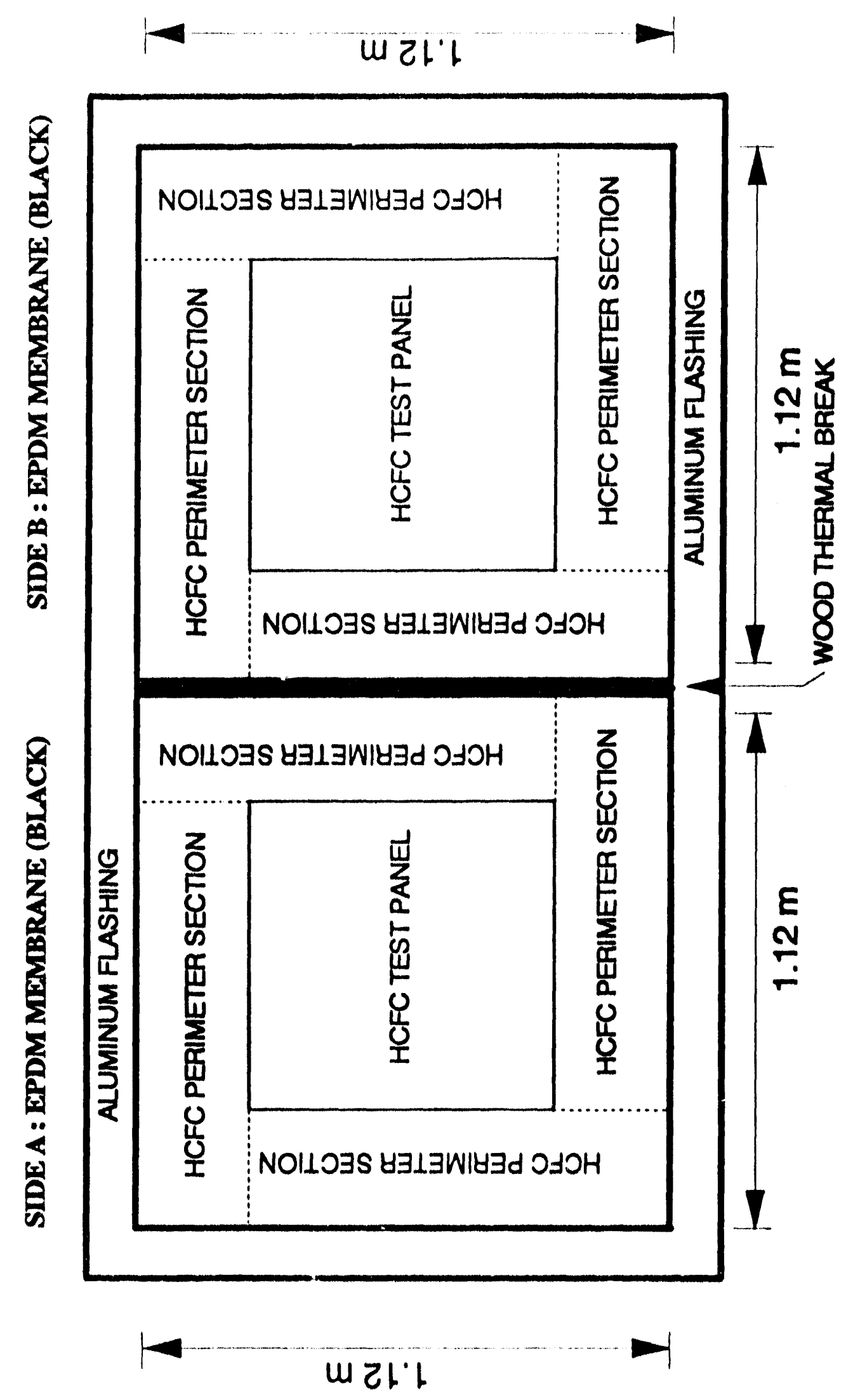




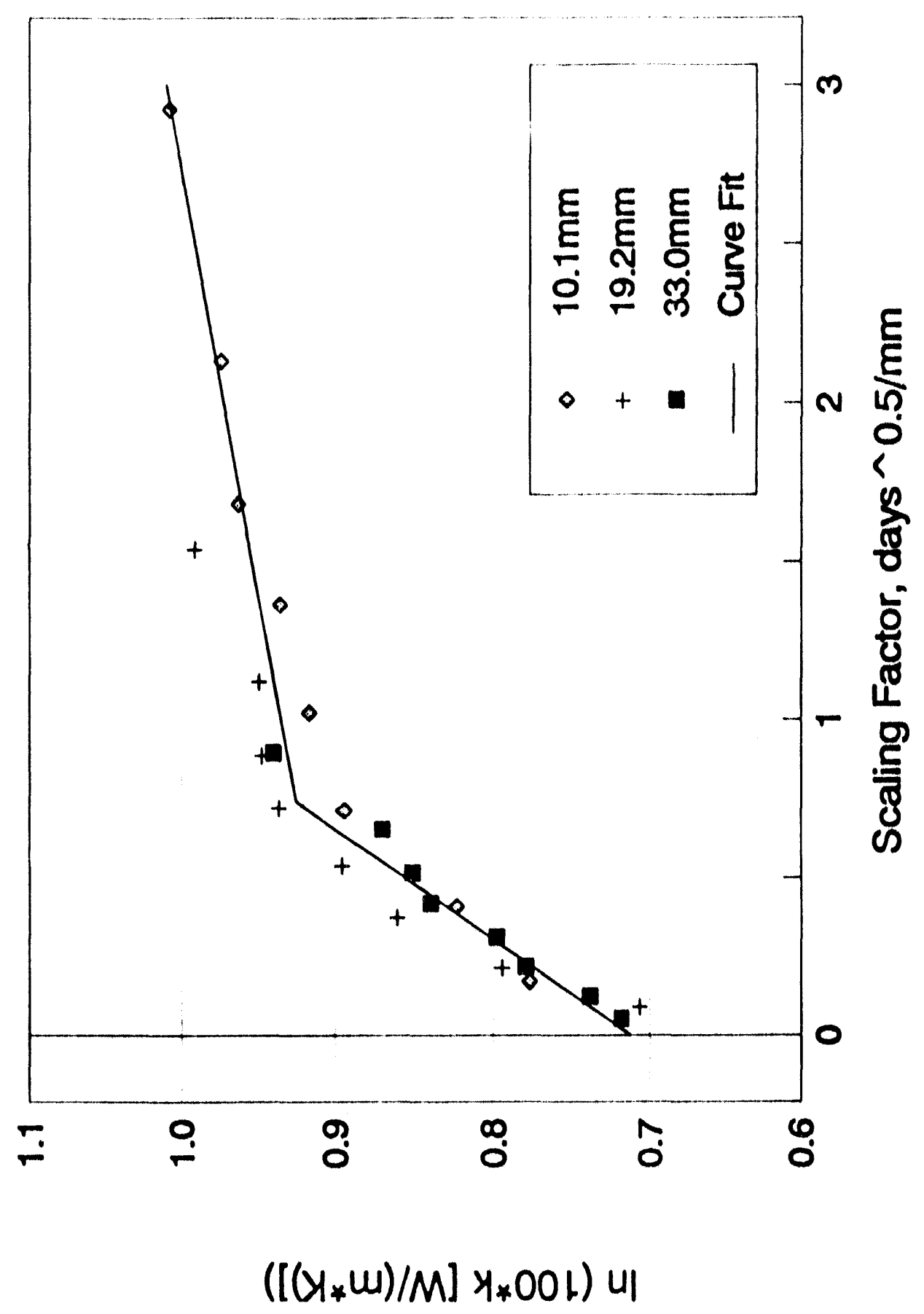




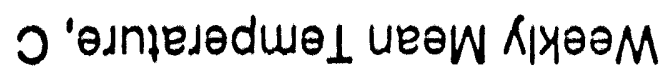

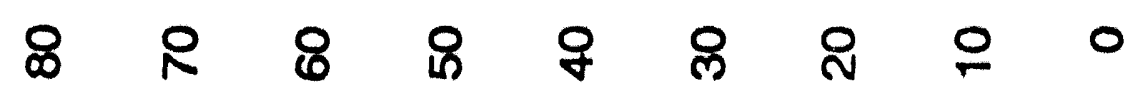

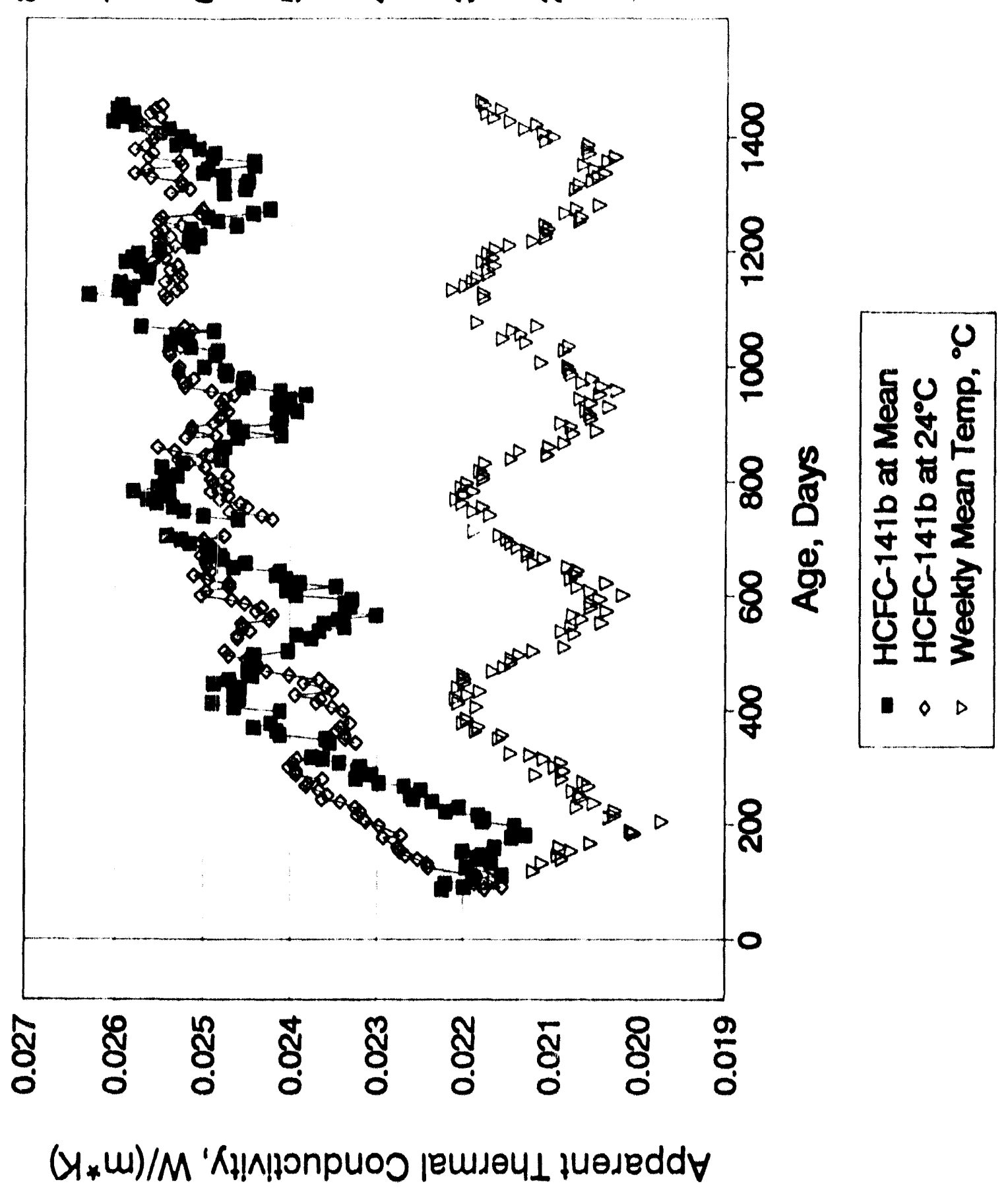




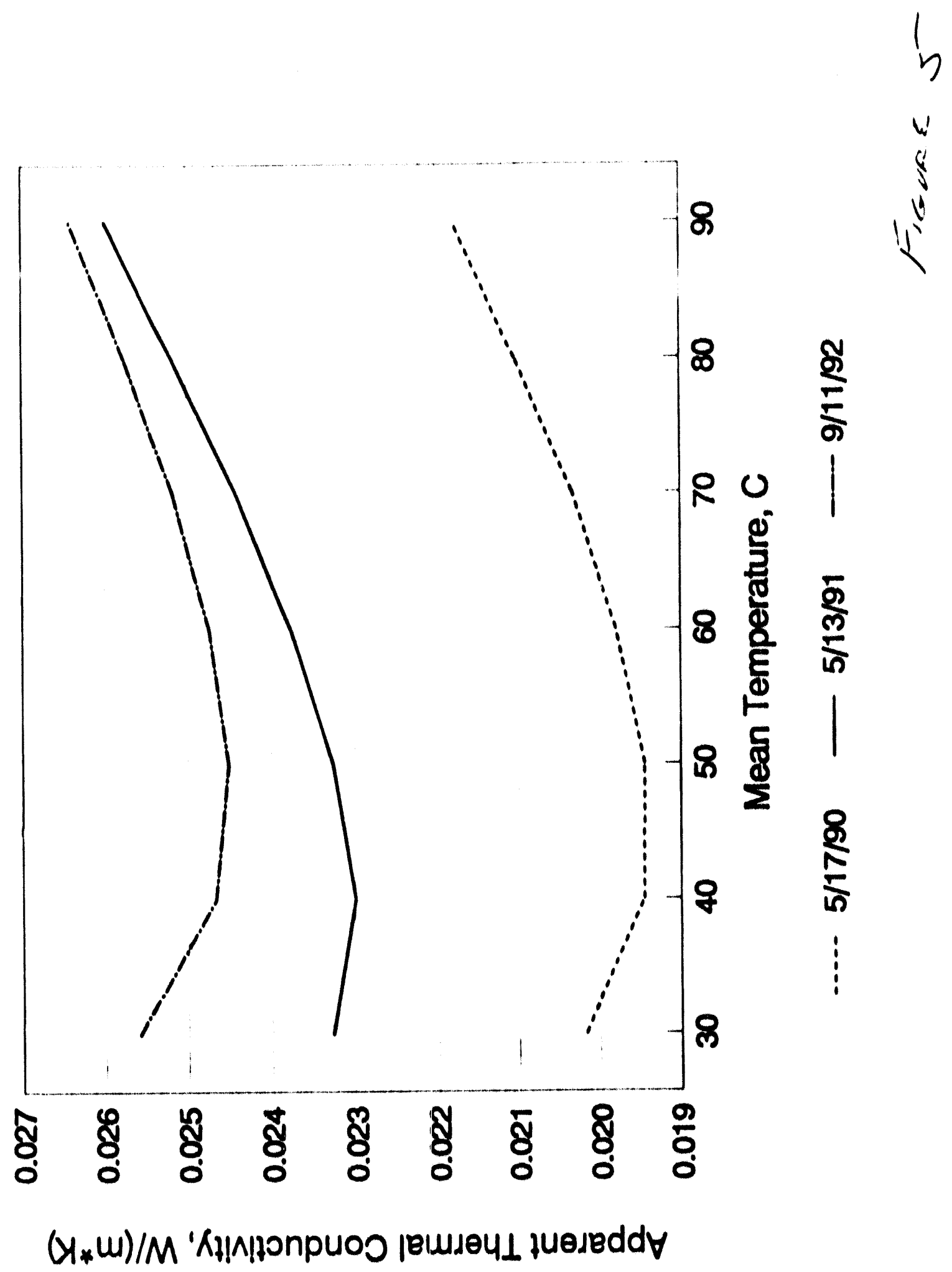




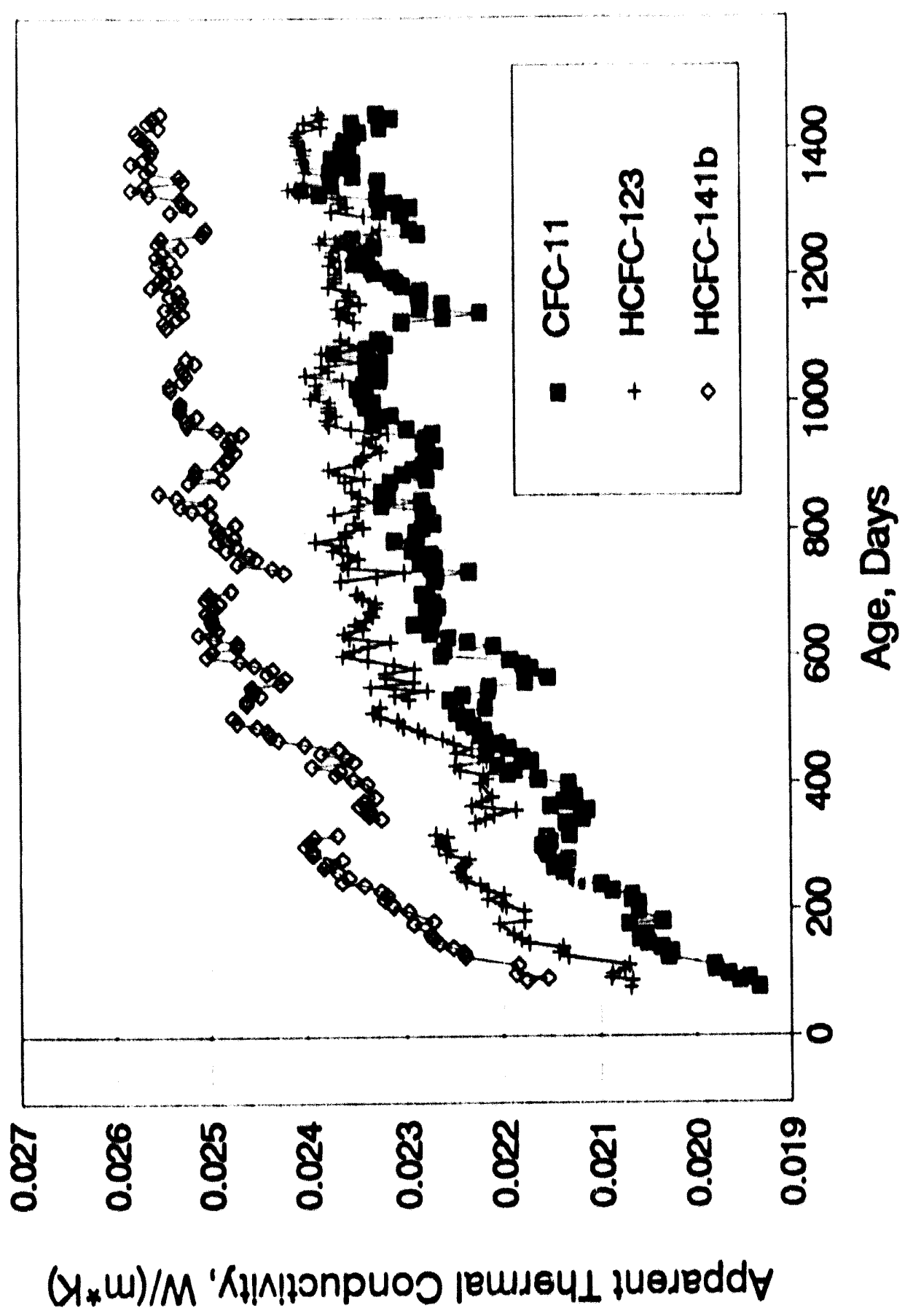




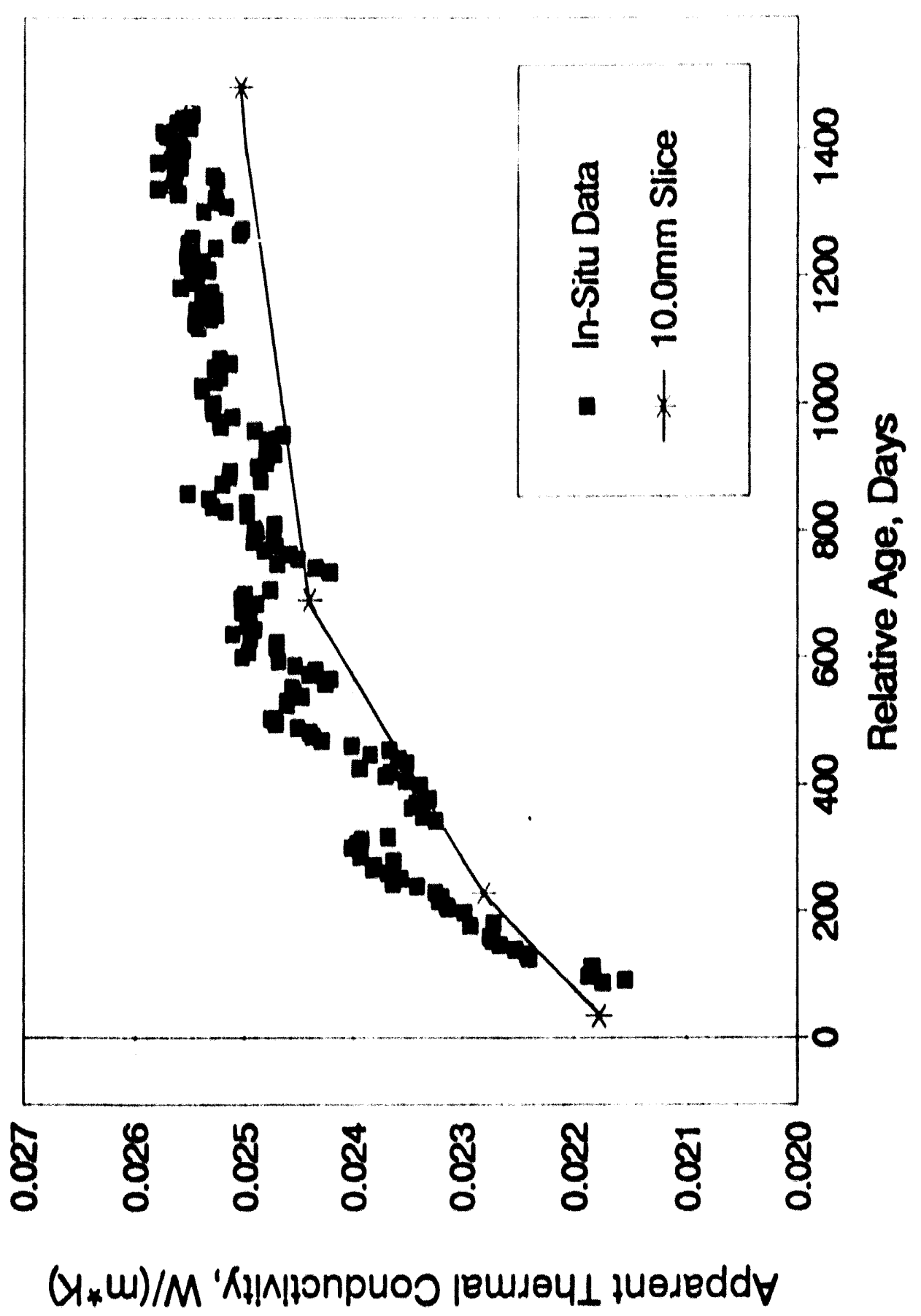




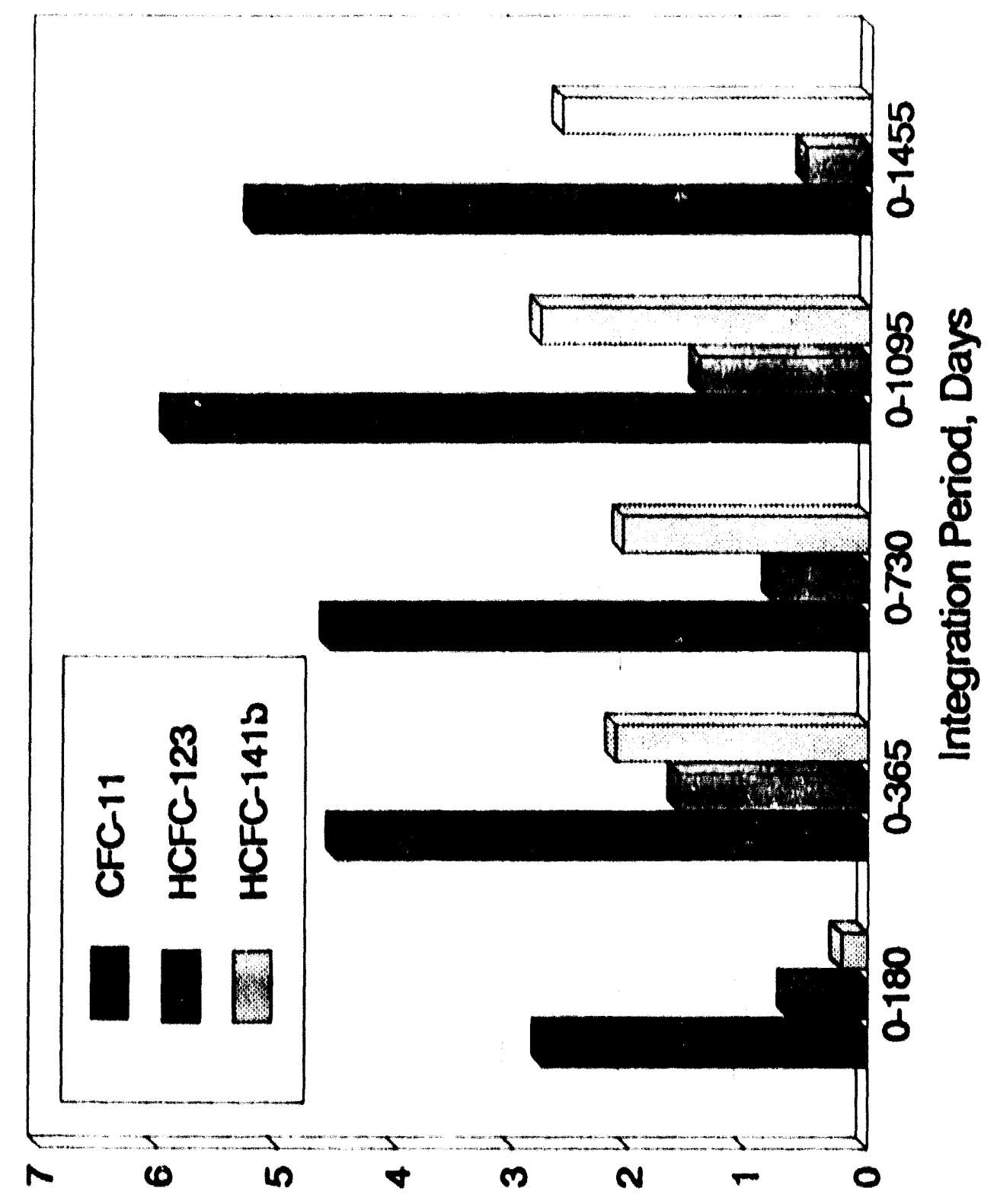

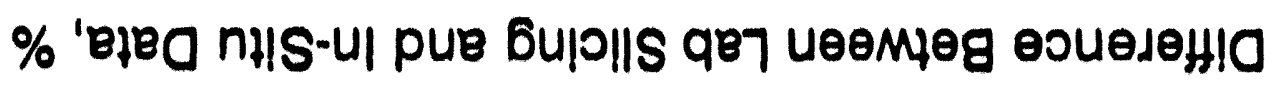




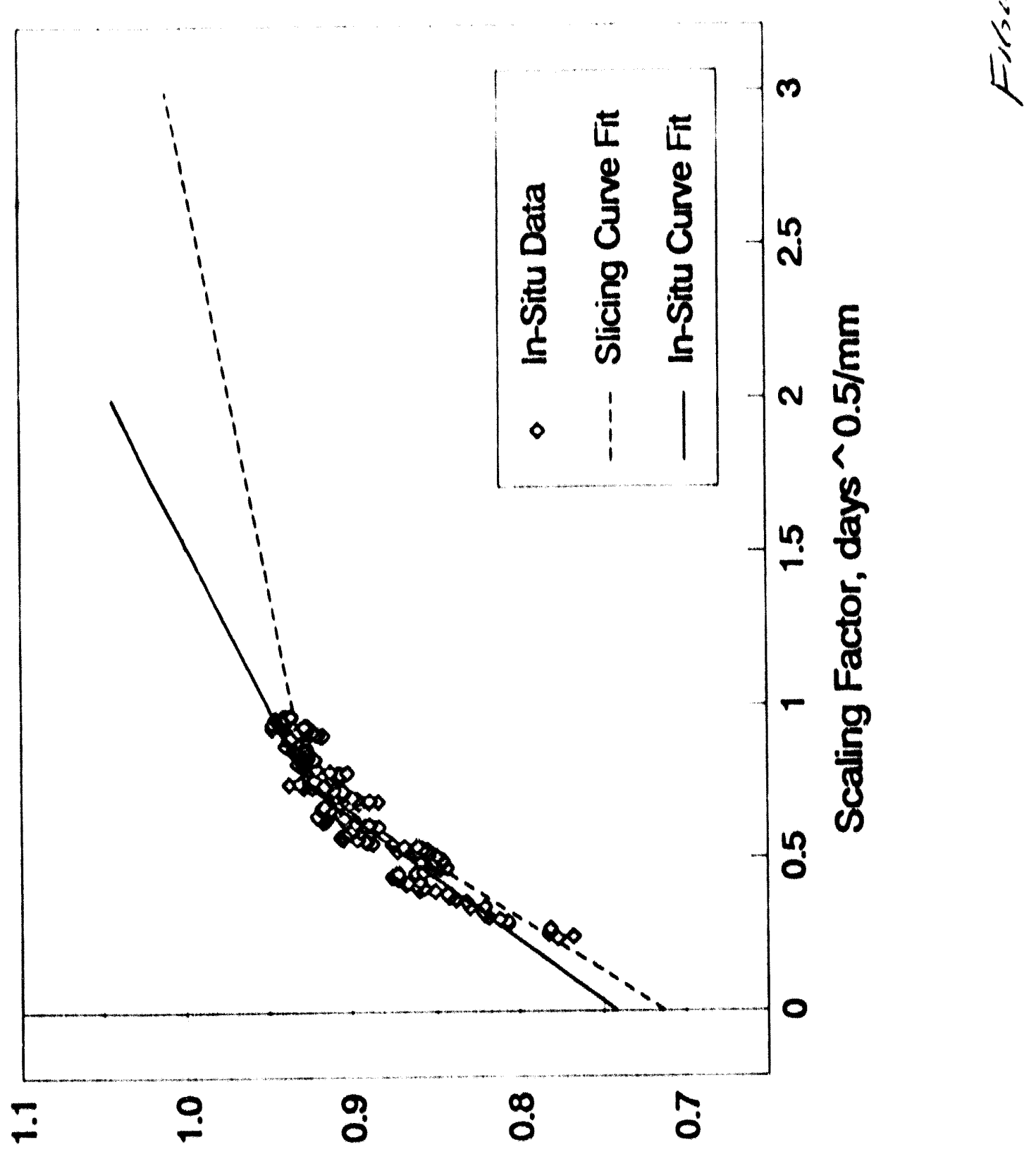

$\left(\left[\left(y_{*}(U) / M\right] y_{*} 00 L\right) u\right.$ 


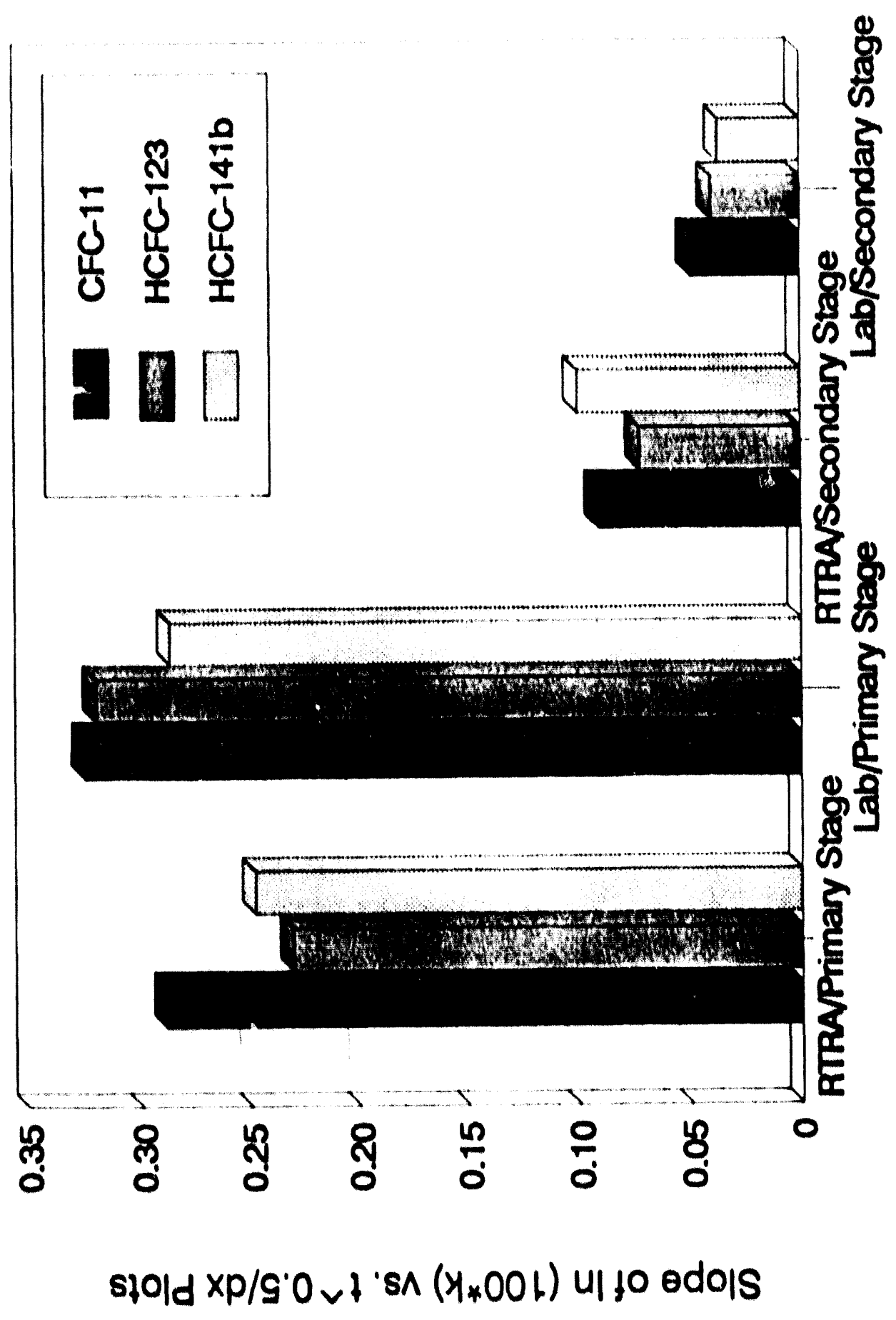



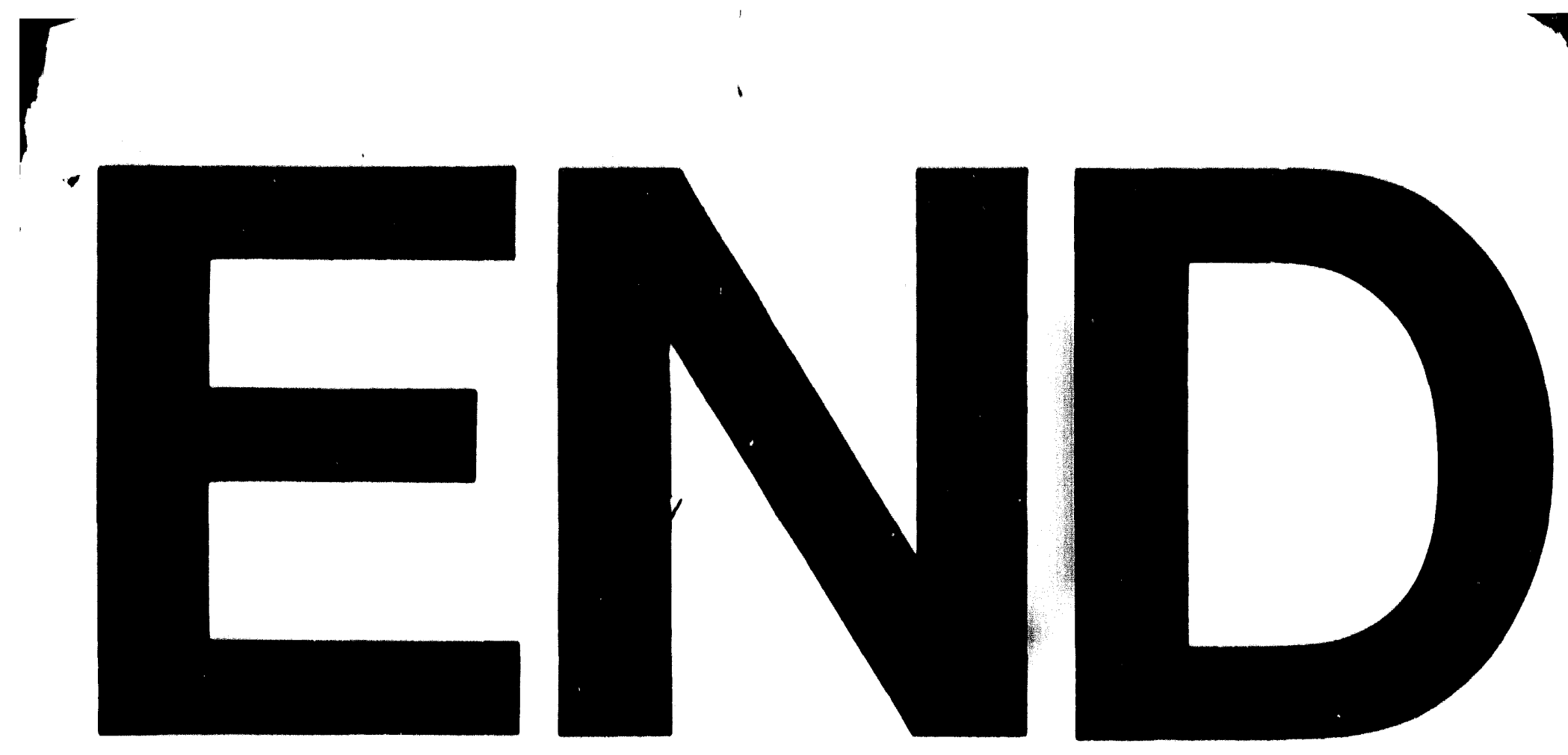

1
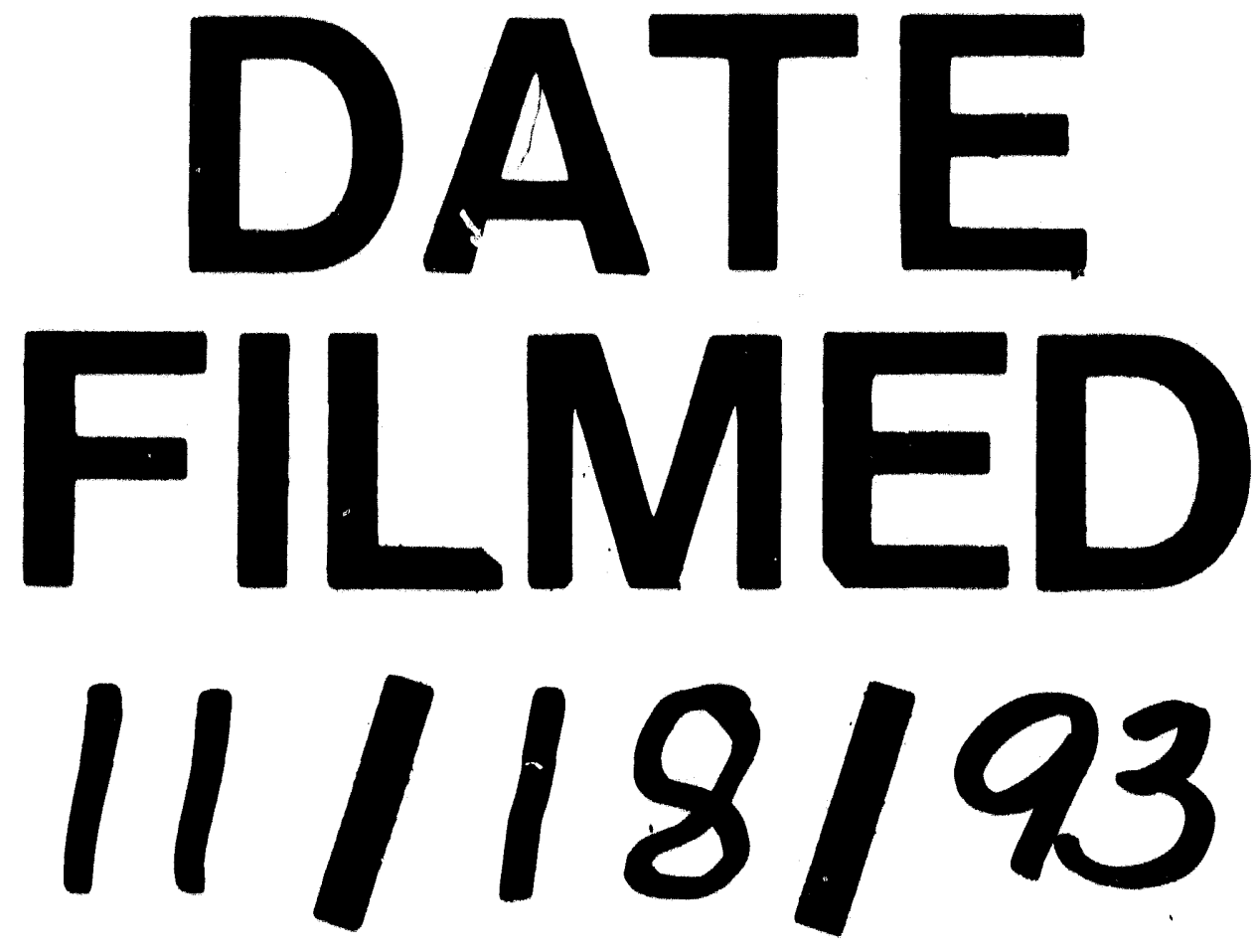

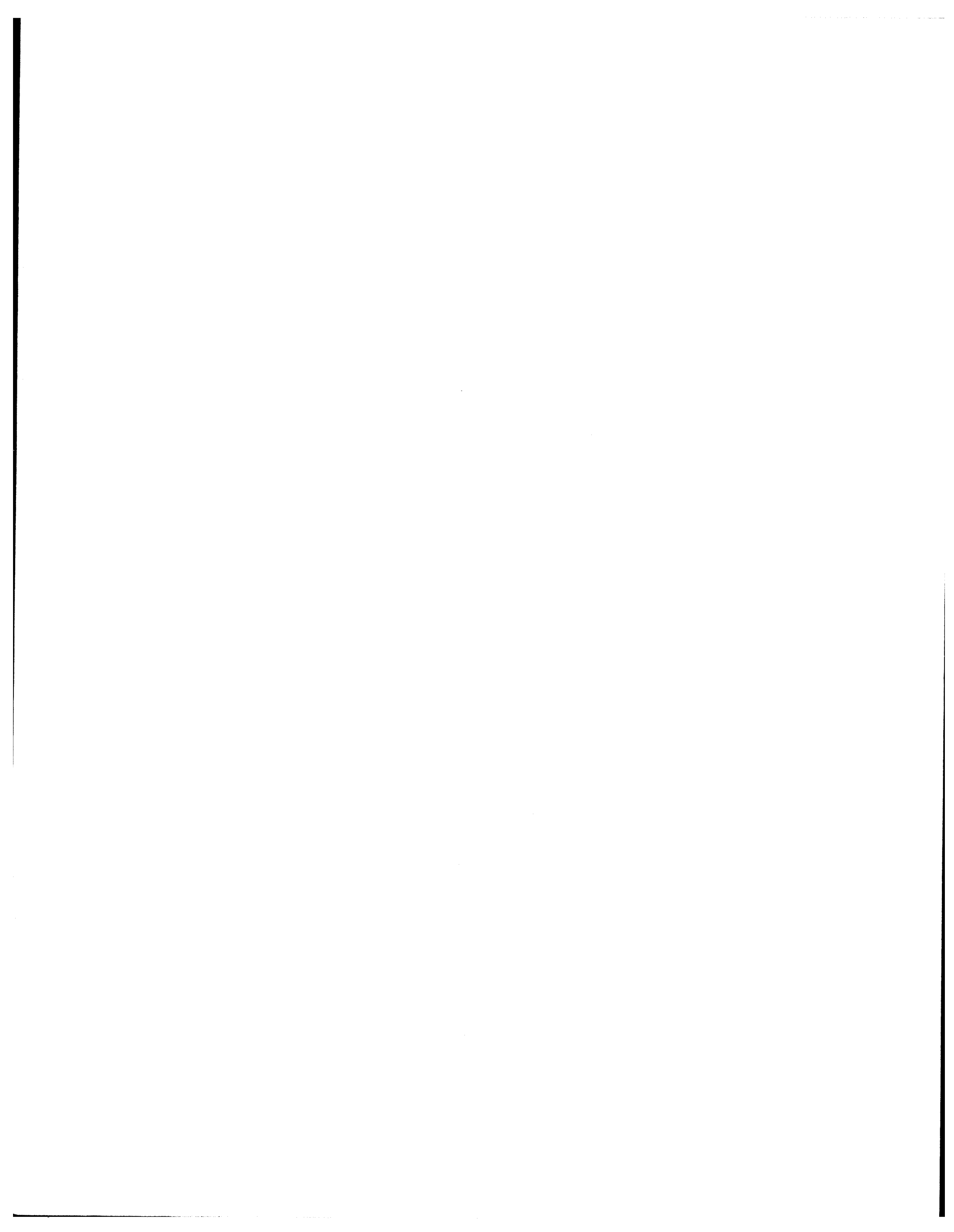